\title{
Social and economic aspects in the families with mentally retarded children
}

\author{
Claudia Teodora Pusta*1, Ioana Mihaela Tomulescu², Mihai Marian³, \\ Gabriel Roseanu ${ }^{3}$ and Hadrian Vaida ${ }^{3}$
}

Address: ${ }^{1}$ Department of Anatomy, Faculty of Medicine and Pharmacy, University of Oradea, Oradea, Romania, ${ }^{2}$ Department of Biology, Faculty of Sciences, University of Oradea, Oradea, Romania and ${ }^{3}$ Department of Psychology, Faculty of Social and Humans Sciences, University of Oradea, Oradea, Romania

* Corresponding author

from International Society on Brain and Behaviour: 3rd International Congress on Brain and Behaviour

Thessaloniki, Greece. 28 November - 2 December 2007

Published: 17 April 2008

Annals of General Psychiatry 2008, 7(SuppI I):S267 doi:10.1 186/I744-859X-7-SI-S267

This abstract is available from: http://www.annals-general-psychiatry.com/content/7/SI/S267

(C) 2008 Pusta et al.; licensee BioMed Central Ltd.

\section{Background}

Mental retardation is a developmental disability that first appears at children under the age of 18 . Because of the complexity of human body, there are many questions about the causes of mental retardation appearance.

\section{Materials and methods}

To realise this study, we investigated 596 children hospitalized on period of 1999-2001 in Neuropsychiatry Infantile Section of Neurology and Psychiatry Clinical Hospital from Oradea. Among these, 393 have different types of mental retardation. We realised family investigation and followed the hereditary antecedents, the harmful factors, alcohol consumption by mother, smoking and social and economic situation of families with mentally retarded children.

\section{Results}

Among 393 cases with mental retardation from studied group, 136 present at least one harmful factor in their family. In the group of mentally retarded children, this represents a rate over $34 \%$. We observed increased rates of many previous pregnancies of mother, precarious economic situation and alcohol consumption. The rate of cases with severe mental retardation who present harful factors in family is lower than rate of cases with moderate mental retardation, but higher than rate of cases with mild mental retardation. This may be an argue for the hypothesis which claims that severe mental retardation is caused in very important share by genetic factors. The results show that a quarter from the cases without antecedents and harmful factors in their families proceeded from orphanages or other shelter institution. So, we can't be sure about the etiology of mental retardation of these children. Among 393 mentally retarded children, 70 (17,8\%) are gipsies.

\section{Conclusions}

Results are very meaningful and they show the importance of precarious living level in the families with mentally retarded children. The precarious living level affects the physical and psyhical health of these children. Also, there is a very high tragic rate of illiteracy in families with mentally retarded children. Many previous pregnancies, precarious economic and social situation and alcohol consumption by mother are the most important harmful factors which determine different types of mental retardation. Many of children who proceeded from orphanages or other shelter institutions have parents without jobs, or they are a result of unwished pregnancies of women with a subcultural level. Many of those children proceeded from parents who have themselves different types of mental retardation and aren't capable to rise a child. Harmful factors, family antecedents, age of parents and genetic factors work together or separately in determination of mental retardation. 